\title{
Nyanyian sebagai Media Pembelajaran Pendidikan Agama Kristen di Sekolah
}

\author{
Branckly Egbert Picanussa \\ Institut Agama Kristen Negeri Ambon \\ Correspondence: brancklyegbert@gmail.com
}

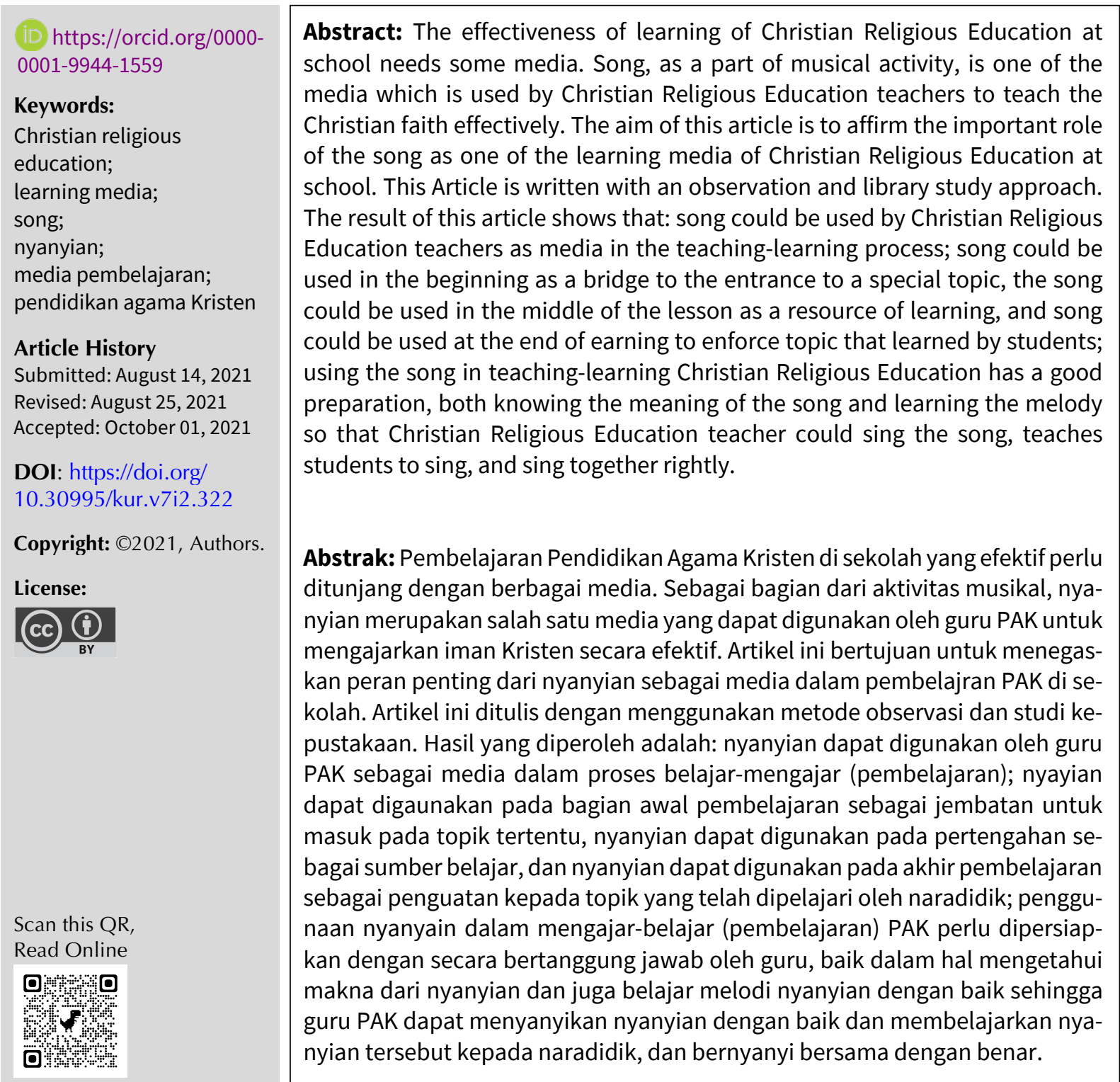

\section{Pendahuluan}

Kegiatan belajar-mengajar Pendidikan Agama Kristen (PAK) di Sekolah pada hakikatnya adalah suatu kegiatan edukatif Kristiani yang melibatkan berbagai komponen, antara lain guru PAK, naradidik, tujuan, bahan atau materi pelajaran, metode, media serta evaluasi. Pembelajaran mengharuskan guru PAK untuk merencanakan tujuan, bahan/materi pelajaran, metode, media 
serta evaluasi sebagai suatu kesatuan yang tidak terpisahkan. Disertakannya nyanyian di dalam buku pembelajaran PAK di sekolah-sekolah sebenarnya merupakan sebuah keniscayaan bagi penggunaan nyanyian sebagai media pembelajaran. Nyanyian-nyanyian yang disertakan dalam buku-buku pembelajaran PAK telah diupayakan agar sesuai dengan materi yang diajarkan kepada naradidik. Pada tingkat Sekolah Dasar, nyanyian yang disertakan di dalam buku pembelajaran antara lain: Hati-hati Tanganku, Dengar Dia Panggil Nama Saya, Ya Tuhan Kau Lihat, Tanganku Hendak Kupakai, Tuhan Betapa Banyaknya, Padamulanya, Sungguh Indah Alam Ciptaan Tuhan, Tuhan Pencipta Semesta, Allahku Besar, Bersyukur kepada Tuhan, Tuhan Cinta Semua Anak, Apalah Arti Ibadahmu, Apakah Yang Kau Lakukan, Kitab Suci Hartaku. ${ }^{1}$

Pada tingkat SMP, nyanyian yang disertakan dalam buku teks pembelajaran antara lain: Dihapuskan Dosaku, Meski Tak Layak Diriku, Burung Pipit Yang Kecil, Jika Padaku Ditanyakan, Tak 'Ku Tahu 'Kan Hari Esok, Pelangi Kasih, Datanglah Ya Roh Kudus, Roh Kudus Hadir Di Sini, Yesus Yang Termanis, Aku Gereja, Kau Pun Gereja, Gereja Bagai Bahtera, Batu Penjuru Gereja, Di Jalan Hidup Yang Lebar-Sempit, Mengasihi Lebih Sungguh. ${ }^{2}$ Sementara untuk tingkat SMA, nyanyian yang disertakan dalam buku teks pembelajaran antara lain Setia Mu Tuhanku Tiada Bertara, Setialah, Aku Gereja Kaupun Gereja, Roh Kudus Sinarilah, Bila Yesus Berada Di Tengah Keluarga, Inilah Rumah Kami, Syukur PadaMu Ya Allah, Keluarga Yang Damai, Keluarga Allah, Ku Cinta K'luarga Tuhan, Di Doa Ibuku. ${ }^{3}$

Sayangnya, dari observasi terhadap guru-guru PAK, dalam pembelajaran PAK diperoleh beberapa hal yang memprihatinkan, seperti: ada guru yang menyebut judul nyanyian dan hanya mengajak anak-anak untuk bernyanyi sementara guru yang bersangkutan tidak bernyanyi; ada guru yang bernyanyi tetapi ada nada-nada yang keliru dinyanyikan; ada guru yang bernyanyi bersama naradidik tetapi ada ritme dari nyanyian yang dinyanyikan keliru; ada guru yang bernyanyi bersama naradidik tetapi nada dan ritme keliru dinyanyikan; guru hanya sekadar menyanyikan nyanyian dan belum menjiwai nyanyian yang dinyanyikan. Penelusuran lebih lanjut terhadap beberapa guru diperoleh informasi yang tidak kalah menarik, seperti: masih ada guru yang berpendapat bahwa nyanyian hanyalah untuk mengisi waktu semata; ada guru PAK yang jarang menggunakan nyanyian karena merasa nyanyian tidak penting dalam pembelajaran PAK; ada guru PAK yang malu untuk bernyanyi karena merasa suaranya tidak bagus atau suaranya seringkali tidak dapat membunyikan nada dengan tepat; ada guru PAK yang tidak bisa menyanyikan notasi musik dengan benar sehingga tidak mempelajari nyanyian yang ada di dalam buku dan tidak mengajarkan nyanyian tersebut kepada anak; ada guru PAK yang bisa menyanyikan notasi musik dan nyanyian dengan benar tetapi malu untuk bernyanyi atau mengekspriskan nyanyian yang dinyanyikan karena merasa tidak berbakat untuk bernyanyi; ada guru PAK yang ingin mengajarkan nyanyian tetapi belum mengetahui bagaimana cara yang paling mudah untuk mengajarkannya. ${ }^{4}$

\footnotetext{
${ }^{1}$ Robinson Napitupulu, Deicy Lidia Bessie, Pendidikan Agama Kristen dan Budi Pekerti SD Kelas I (Jakarta: Kementiran Pendidikan dan Kebudayaan, 2014); Robinson Napitupulu, Veronica Hematang, Pendidikan Agama Kristen dan Budi Pekerti SD Kelas III (Jakarta: Kementrian Pendidikan dan Kebudayaan, 2014); Norita Yudiet Tompah, Erich Von Martin, Pendidikan Agama dan Budi Pekerti SD Kelas III (Jakarta: Kementrian Pendidikan dan Kebudayaan, 2015).

2 Janse Belandina Non-Serrano dan Erich Von Martin E. Hutahaean, Pendidikan Agama Kristen dan Budi Pekerti SMP Kelas VII (Jakarta: Kementrian Pendidikan dan Kebudayaan, 2014); Julia Suleeman Chandra, Janse Belandina Non-Serrano, Stephen Suleeman, Pendidikan Agama Kristen dan Budi Pekerti Kelas VIII (Jakarta: Kementrian Pendidikan dan Kebudayaan, 2014); Pendidikan Agama Kristen dan Budi Pekerti Kelas Kelas IX (Jakarta Kementrian Pendidikan dan Kebudayaan, 2015).

${ }^{3}$ Janse Belandina Non-Serrano, Stephen Suleeman, Pendidikan Agama Kristen dan Budi Pekerti Kelas IX (Jakarta: Kementrian Pendidikan dan Kebudayaan, 2014); Dien Sumiyatiningsih, Stepahnus, Pendidikan Agama Kristen dan Budi Pekerti Kelas X (Jakarta: Kementrian Pendidikan dan Kebudayaan, 2014); Jansen Belandina NonSerrano, Julia Suleeman, Robert P. Borrong, Pendidikan Agama Kristen dan Budi Pekerti Kelas XII (Jakarta: Kementrian Pendidikan dan Kebudayaan, 2015).

${ }^{4}$ Hasil obervasi terhadap Guru PAK yang mengikuti kegiatan Pendidikan Profesi Guru dalam Jabatan yang dilakukan oleh IAKN Ambon - LPTK Induk, tahun 2018, 2019, 2020, dan 2021.
} 
Penelitian terkait penggunaan nyanyian dalam pembelajaran memang telah dilakukan, misalnya tentang Penggunaan Teknik Nyanyian dalam Meningkatkan Kefahaman Murid Tahun Kedua dalam Topik Pembundaran yang ditulis oleh Reney Pantun ${ }^{5}$; Kemahiran Berfikir Tingkat Aras Tinggi (KBAT) dalam Salak Didik dengan Elemen Nyanyian dan Elemen Pantun yang ditulis oleh A. Rahman Haron, Jamaludi Badusah, dan Zamri Mahamod ${ }^{6}$; dan The use of song in teaching english for junior high school student, artikel yang ditulis oleh Muhamad Sofian Hadi. ${ }^{7}$ Akan tetapi, artikel khusus tentang penggunaan nyanyian di dalam pembelajaran PAK di Sekolah di Indonesia sangatlah jarang; kalau tidak, hendak mengatakan tidak ada.

Berdasarkan pada beberapa hal tersebut di atas, artikel ini bertujuan untuk menginformasikan beberapa hal terkait dengan nyanyian dalam pembelajaran PAK dan menyampaikan beberapa solusi untuk meminimalisir kekeliruan yang dilakukan oleh guru PAK dan juga untuk memberikan cara praktis pemanfaatan nyanyian sebagai media yang efektif dalam pembelajaran PAK di sekolah.

\section{Metode Penelitian}

Data penelitian ini diperoleh melalui obervasi dan juga penelitian kepustakaan. Observasi dilakukan secara langsung dan tidak langsung untuk memperoleh data terkait dengan penggunaan nyanyian di dalam pembelajaran dan juga keberadaan guru dalam penggunaan nyanyian dalam pembelajaran. Sementara studi kepustakaan dilakukan untuk mendapatkan berbagai informasi terkait dengan nyanyian dan pembelajaran serta implementasinya untuk pembelajaran. ${ }^{8}$ Artikel ini dimulai dengan gagasan hakikat dan tujuan Pendidikan Agama Kristen yang berujung pada pendidikan yang berkualitas, pendidikan yang mendidik para naradidik untuk menjadi bijak di dalam iman Kristen. Selanjutnya, penulis memaparkan tentang musik dalam kehidupan bergereja dan dilanjutkan dengan musik dalam sejarah perkembangan pikiran dan praktek PAK sebagai upaya untuk mempertegas pentingnya musik dalam kehidupan orang-orang Kristen, di gereja dan juga dalam komunitas Kristen, termasuk di sekolah. Sebelum berakhir dengan kesimpulan, akan disajikan, sekaligus menegaskan, penggunaan nyanyian sebagai media pembelajaran PAK di sekolah, serta beberapa saran terkait dengan penggunaan nyanyian dalam pembealjaran PAK.

\section{Pembahasan}

\section{Hakikat dan Tujuan Pembelajaran Pendidikan Agama Kristen}

Adanya mata pelajaran Pendidikan Agama Kristen (PAK) di sekolah-sekolah merupakan sebuah hal yang perlu dikembangkan dengan sebaik-baiknya sehingga pembinaan iman Kristen bagi naradidik Kristen menjadi lebih baik bukan hanya dari segi pengetahuan semata, tetapi juga dari segi sikap dan keterampilan. Tentu saja, upaya pengembangan perlu ditunjang dengan memahami secara baik tentang hakekat dan tujuan dari Pendidikan Agama Krsiten. Salah satu pandangan yang menarik terkait dengan hakekat dan tujuan agama pendidikan agama kristia pernah dikemukakan oleh Thomas H. Groome. Menurutnya, hakikat dari Pendidikan Agama Kristen adalah educating for conation or wisdom in Christian faith. Bagi Groome, Pendidikan Agama Kristen merupakan kegiatan untuk menjadikan orang Kristen bijak di dalam iman Kristen. Oleh karena itu, Pendidikan Agama Kristen adalah pendidikan yang berkualitas untuk membentuk naradidik yang secara utuh memahami keberadaannya (historis, sosial, dan politik) dan secara aktif menya-

\footnotetext{
${ }^{5}$ Reney Pantun dalam http://ojs.umsida.ac.id/index.php/icecrs diakses 25 Oktober 2021.

${ }^{6}$ A. Rahman Haron, Jamaludi Badusah, dan Zamri Mahamod dalam Jurnal Pendidikan Bahasa Melayu -JPBM (Malay Language Education Journal -MyLEJ) diakses 25 Oktober 2021.

${ }^{7}$ Sofyan Hadi dalam https://jurnal.umj.ac.id/index.php/ELIF diakses 25 Oktober 2021.

${ }^{8}$ Bnd. Mestika Zed, Metode Penelitian Kepustakaan (Jakarta: Yayasan Obor Indonesia, 2008).
} 
takan keberadaan tersebut dalam hubungan yang baik, dengan Allah, diri sendiri, orang lain, dan juga ciptaan Allah, kapan dan di mana pun. ${ }^{9}$

Kebajikan (wisdom) dalam tinjauan Alkitabiah menunjuk kepada beberapa hal, antara lain keadaan moralitas, kecapakan teknis (Kel. 31:6), atau kepandaian (2Sam. 14:2), kebajikan yang membawa pada kesuksesan hidup, reskpek, keberadaan pribadi (Ayub 12:12) juga belajar dari tradisi (Ams. 19:20). Kebajikan juga menunjuk kepada dimensi intelektual dan praktikal (Hak. 10:3). Kebajikan menjadi pusat dari sikap atau afeksi (Mzm. 4:7). Lebih lanjut, Kebajikan adalah anugerah dari Allah dan respon etis manusia kepada penyataan dan hukum Allah (Ams. 2; Ay. 28:28). Tidak kalah menarik juga, Groome menginformasikan bahwa di dalam Perjanjian Baru, Paulus menggambarkan Yesus sebagai "the wisdom of God" (1Kor. 1:24), dan bagi Yakobus, kebajikan Kristen berkaitan dengan damai, sukacita, kebaikan, dan keadilan. Bagi Groome, dari perspektif Perjanjian Lama dan Perjanjian Baru serta tradisi Kristiani, wisdom dipahami sebagai anugerah Allah yang membimbing manusia untuk mengetahui kebenaran dan hidupa dalam relasi yang baik dengan Allah, diri sendiri, orang lain, dan juga ciptaan Allah. ${ }^{10}$

Pendidikan Agama Kristen atau Christian Religious Education yang oleh Groome diartikan sebagai educating for conation or wisdom in Christian faith memiliki 3 (tiga) tujuan, yakni menyatakan Pemerintahan Allah, mewartakan iman Kristen, dan menyatakan pembebasan manusia secara utuh. Bagi Groome, sangatlah penting para pendidik agama Kristen untuk melihat hubungan antara kehendak Allah di dalam Alkitab dan manusia sebagai kawan sekerja dalam mewujudkan Pemerintahan Allah di dunia ini. Selain itu, Pendidikan Agama Kristen juga bertujuan untuk mengasuh naradidik sehingga dalam seluruh keberadaannya mewartakan berbagai dimensi iman Kristen (kognitif/mental, afektif/relational, dan behavioral/obediential). Selanjutnua, tujuan dari Pendidikan Agama Kristen adalah melaksanakan pendidikan yang mentransformasikan pembebasan Kristen baik secara personal, interpersonal, maupun sosiopolitis dan budaya sehingga naradidik mengalami pembaruan hidup. ${ }^{11}$

Pendapat Groome tersebut mengisyartakan pentingnya pelaksanaan Pendidikan Agama Kristen (PAK) secara bertanggung jawab dan tidak dilakukan secara asal-asalan karena mendidik seseorang agar menjadi bijak di dalam iman Kristen merupakan hal yang sangat penting dan hal tersebut tidaklah mudah serta membutuhkan berbagai komponen. Salah satu di antara berbagai komponen tersebut adalah musik.

\section{Musik dalam Kehidupan Bergereja}

Musik merupakan salah satu unsur penting dalam kehidupan bergereja. Kenneth O. Gangel berpendapat bahwa musik selalu erat berhubungan dengan agama Kristen. Rasul Paulus telah mendorong orang-orang percaya di Kolose untuk membiarkan "perkataan Kristus diam dengan segala kekayaannya di antara kamu, sehingga kamu dengan segala hikmat mengajar dan menegur seorang akan yang lain dan sambil menyanyikan Mazmur, dan puji-pujian dan nyanyian rohani, kamu mengucap syukur kepada Allah di dalam hatimu" (Kol. 3:16). Orang-orang yang tidak bisa memainkan alat-alat musik dan yang tidak bisa bernyanyi dapat menikmati musik yang disajikan oleh orang lain. Keefektifan musik bergantung sebagian besar pada cara dan tingkat musik itu dimainkan. Musik Kristen itu khusus dan tidak boleh dicampuradukan dengan bentuk musik dunia. ${ }^{12}$ Kekhususan musik kristen penting untuk dikembangkan karena, sebagaimana dikemuka-

\footnotetext{
${ }^{9}$ Thomas H. Groome, Sharing Faith: A Comprehensive Approach to Religious Education \& Pastoral Ministry: The Way of Shared Praxis (New York: HarperCollins Publishers, 1991), 11-35; Bnd. Charless F. Melchert, Wise Teaching: Biblical Wisdom and Educational Ministry (Pannsylvania: Trinity Press International, 1998), $273-307$.

10 Ibid, 31-32.

${ }^{11}$ Thomas H. Groome, Ibid., 11-35.

${ }^{12}$ Kenneth O. Gangel, Building Leadership for Chruch Education (Chicago:Moody Publhiers, 1970), 60-62.
} 
kan oleh Ronald W. Leigh, musik merupakan metode bagi gereja untuk menyampaikan pesanpesan kristiani. ${ }^{13}$

Nyanyian memiliki pengaruh yang sangat besar untuk umat manusia. ${ }^{14}$ Nyanyian tidak terpisahkan dari hidup manusia, sepanjang umur, mulai dari masa kanak-kanak. Nyanyian merupakan salah satu cara yang penting untuk mengungkapkan pikiran dan perasaan, baik perorangan maupun bersama-sama. ${ }^{15}$ Sejalan dengan hal tersebut, J. M. Pattiasina berpendapat bahwa nyanyian dan musik gerejawi merupakan unsur yang amat penting dalam kehidupan kerohanian dan peribadahan umat Kristen di segala abad dan jaman. ${ }^{16}$

Musik merupakan salah satu komponen penting dalam kehidupan bergereja dan komunitas Kristiani, termasuk di guru PAK dan naradidik Kristen di sekolah. Musik merupakan media yang mempersatukan orang-orang Kristen (koinonia); musik merupakan media bagi orang-orang Kristen untuk melayani (diakonia); dan musik merupakan media bagi orang-orang Kristen untuk bersaksi (marturia). Musik penting bagi gereja karena musik merupakan salah satu cara gereja dan komunitas kristiani menyampaikan iman Kristen. ${ }^{17}$ Gereja, termasuk di dalamnya komunitas Kristiani, tanpa musik bagikan burung tanpa sayap, sebagaimana dikemukakan oleh Hendry van Dyke berpendapat, "A church without music is like a bird without wings." 18

\section{Musik dalam Sejarah Perkembangan Pikiran dan Praktek PAK}

Penggunaan musik (nyanyian) sebagai media pembelajaran dalam dunia pendidikan, termasuk di dalamnya Pendidikan Agama Kristen, pernah dikemukakan oleh Roberth R. Boehlke. Menarik untuk disimak, penggunaan nyanyian merupakan hal yang penting yang tidak terpisahkan dari aktivitas pendidikan untuk merubah orang-orang Kristen ke arah yang lebih baik. Bagi Plato, musik diperlukan dalam usaha untuk mengembangkan emosi naradidik.

Emosi para anak didik harus dikembangkan melalui musik...Musik pun turut mengembangkan emosi. Ketiga unsur musik, yaitu kata-kata, lagu dan iramanya perlu disesuaikan satu sama lain sehingga anak didik terdorong untuk mencapai kehidupan yang berbudi tinggi. Tidak semua musik dapat memenuhi tugas itu. Ada musik yang menghantar orang untuk mengalami kebajikan; musik yang tidak demikian harus ditolak. ${ }^{19}$

Pernyataan Plato mengisyarakatkan kepada kita agar menggunakan musik, dalam hal ini nyanyian, secara bertanggung jawab untuk mengembangkan emosi dari naradidik yang kita ajarkan. Nyanyian merupakan media untuk membuat kehidupan naradidik menjadi lebih baik. Nyanyian yang digunakan dalam pembelajaran sebaiknya dapat mempengaruhi naradidik menjadi bijak. Tak heran jika kemudian Quitilianes, dalam kesadarannya, telah memasukkan musik sebagai salah satu mata pelajaran penting yang harus ada di dalam kurikulum. ${ }^{20}$

Guru Pendidikan Agama Yahudi memanfaatkan nyanyian sebagai media pembelajaran. ${ }^{21}$ Lebih lanjut, dalam kehidupan Gereja Purba, nyanyian merupakan media pembelajaran iman ${ }^{22}$ dan juga sebagai media untuk memupuk kehendak dan pikiran. ${ }^{23}$ Pemanfaatan musik pun

\footnotetext{
${ }^{13}$ Ronald W. Leigh, terjemahan Stephen Suleeman, Melayani dengan Efektif (Jakarta: BPK Gunung Mulia, cetakan III, 1996), 213-216; Bnd. Robert Woods, Bran Walrath, The Message in the Music: Studying Contemporary Praise \& Wroship (Nashville: Abingdon Press, 2007).

${ }^{14}$ Andreas A. Yewangoe dalam Kata Pengantar Buku Nyanyian Kidung Sekolah Minggu (Jakarta: Yamuger, Cetakan I, 2008)

${ }^{15}$ Yayasan Musik Gereja dalam Prakata Kidung Ceria (Jakarta: Yamuger, Cetakan XI, 1985).

${ }^{16}$ J.M. Pattiasina dalam Kata Pengantar Pelengkap Kidung Jemaat (Jakarta: Yamuger, cetakan IV, 2007)

${ }^{17}$ Bnd. Mawene. M.Th., Gereja yang Bernyanyi: Menghidupkan Ibadah dengan Lagu (Yogyakarta, ANDI Offset, Cetakan IV, 2007).

${ }^{18}$ Hendry van Dyke, "Music as an Aid to Faith" dalam Stanley Armstrong Hunter.editor. Music and Religion (New York: Abingdon Press, 1930), 27.

${ }^{19}$ Robert R. Boehlke, Sejarah Perkembangan Pikiran dan Praktek Pendidikan Agama Kristen: Dari Plato sampai IG. Loyola. Cetakan ke-8 (Jakarta: BPK Gunung Mulia, 2006), 7.

${ }^{20}$ Ibid., 17.

${ }^{21}$ Ibid., 47.

${ }^{22}$ Ibid., 100.

${ }^{23}$ Ibid., 121.
} 
berlanjut dalam pendidikan kristiani abad pertengahan. Pada zaman Reformasi Protestan, Luther menjadi salah satu tokoh yang sangat memperhatikan pentingnya musik termasuk di dalamnya nyanyian bagi pengembangan iman Kristen secara aktif. ${ }^{24}$ Pentingnya nyanyian dalam pendidikan kristiani pun dikembangkan oleh Pestalozzi dengan mengikutsertakan nyanyian rohani di dalam kurikulum. ${ }^{25}$ Sementtara Miller, yang oleh Boehlke dikelompokkan sebagai pemikir Menuju Kematangan Pendidikan Agama Kristen (III), berpendapat bahwa musik merupakan media yang amat penting bagi pendidikan kristiani. ${ }^{26}$

Informasi yang diberikan oleh Boehlke memperlihatkan betapa musik telah menjadi salah satu komponen yang penting dalam pelaksanaan PAK. Musik, dalam hal ini nyanyian, menjadi salah satu media yang penting untuk mengkomunikasikan iman Kristen dari waktu ke waktu. Tidak mengherankan jika musik memainkan peran yang penting dalam komunitas Kristiani, termasuk di dalamnya orang-orang Kristen di sekolah.

\section{Penggunaan Nyanyian sebagai Media Pembelajaran PAK di Sekolah}

Pemelajaran PAK merupakan sebuah usaha yang dilakukan oleh guru agar naradidik menjadi bijak dalam iman Kristen, menghayati iman Kristen, dan mempraktekkan iman Kristen dalam hidupnya. ${ }^{27}$ Upaya yang dilakukan oleh guru dapat menginspirasi, menyemangati, dan juga mengubah kehidupan naradidik sehingga teradah pada kehidupan yang bijak dan dewasas di dalam iman. ${ }^{28}$ PAK di sekolah merupakan suatu komunikasi dan interaksi serta interelasi edukatif kristiani untuk mencapai tujuan (kognitif, afektif, psikomotor) yang telah ditetapkan. Kegiatan belajar mengajar merupakan proses komunikasi yang selalu melibatkan tiga komponen pokok, yaitu guru, naradidik, dan materi. Agar pembelajaran dapat berlangsung dengan baik, guru perlu mempersiapkan berbagai media sebagai alat pembelajaran.

Rossi dan Breidle berpendapat bahwa media pembelajaran (baca: kegiatan belajar mengajar) adalah seluruh alat dan bahan yang dapat dipakai untuk mencapai tujuan. ${ }^{29}$ Sementara, Gerlach dan Ely berpendapat "A medium, conceived is any person, material or event that establish condition which enable the learner to acquire knowledge, skill, and attitude," ${ }^{\prime \prime 3}$ Artinya, media meliputi banyak hal, bisa orang, bahan, peralatan, atau kegiatan yang menciptakan kondisi di mana siswa dapat memperoleh pengetahuan, keterampilan, dan sikap. Berdasarkan pendapat di atas, bila diaplikasikan pada penggunaan nyanyian, maka nyanyian merupakan media untuk mencapai tujuan pembelajaran yang telah ditetapkan dan memungkinkan naradidik untuk memperoleh pengetahuan, keterampilan, dan sikap yang diajarkan di dalam pembelajaran PAK.

Kehadiran media dalam Pembelajaran PAK di sekolah adalah untuk mencapai tujuan dan memberikan kesempatan kepada naradidik untuk belajar secara optimal. Lebih daripada itu, adanya media pembelajaran dalam pelaksanaan PAK sangatlah penting untuk membelajarkan naradidik sehingga mereka menjadi bijak di dalam iman Kristen, baik dalam berpikir, berkata, maupun berperilaku di dalam kehidupan mereka.

Musik merupakan salah satu media yang dapat digunakan dalam pembelajaran PAK. Bobbi dePorter dkk., berpendapat bahwa musik dapat mempengaruhi guru dan naradidik. Guru dapat

${ }^{24}$ Robert R. Boehlke, Sejarah Perkembangan Pikiran dan Praktek Pendidikan Agama Kristen: Dari Plato sampai IG. Loyola. Cetakan ke-8 (Jakarta: BPK Gunung Mulia, 2006), 350.

${ }^{25}$ Robert R. Boehlke, Sejarah Perkembangan Pikiran dan Praktek Pendidikan Agama Kristen: Dari Yohanes Amos Comenius sampai Perkembangan PAK di Indonesia. Cetakan ke-4 (Jakarta: BPK Gunung Mulia, 2009$), 255$.

${ }^{26}$ Robert R. Boehlke, Sejarah Perkembangan Pikiran dan Praktek Pendidikan Agama Kristen: Dari Yohanes Amos Comenius sampai Perkembangan PAK di Indonesia (Jakarta: BPK Gunung Mulia, 2009), 688, 708.

${ }^{27}$ David I. Smith, James K. A. Smith, Introduction: Practices, Faith, and Pedagogy dalam David I. Smith, James K. A. Smith, editors, Teaching and Christian Practices: Reshaping Faith \& Learning (Grand Rapids: William B. Eerdmans Publishing Company, 2011), 7-11.

${ }^{28}$ Membelajarkan yang efektif menurut beberapa siswa, sebagaimana dikemukakan oleh Susan M. Simonaitis, Teaching as Conversation dalam L. Gregory Jones, Stephanie Paulsell, editors, The Scope of Our Art: The Vocation of the Theological Teacher (Grand Rapids: William B. Eerdmans Publishing Company, 2002), 100.

${ }^{29}$ Rossi dan Breidle dalam Wina Sanjaya, Strategi Pembelajaran Berorientasi Standar Proses Pendidikan (Jakarta: Kencana Prenada Media Group, Cetakan V, 2008), 163.

${ }^{30}$ Gerlach dan Ely dalam Wina Sanjaya, Ibid. 
menggunakan musik untuk menata suasana hati, mengubah keadaan mental siswa, dan mendukung lingkungan belajar. Musik membantu pelajar bekerja lebih baik dan mengingat lebih banyak. Musik merangsang, meremajakan, dan memperkuat belajar, baik secara sadar maupun tidak sadar. Di samping itu, kebanyakan siswa memang mencintai musik. Irama, ketukan, dan keharmonisan musik memengaruhi fisiologis manusia terutama gelombang otak dan detak jantung, di samping membangkitkan perasaan dan ingatan. Musik dapat membantu siswa masuk ke keadaan belajar optimal. Musik juga memungkinkan guru membangun hubungan dengan siswa. Musik juga berpengaruh kuat pada lingkungan belajar, merangsang dan mempertahankan lingkungan belajar agar tetap optimal.

Berkaitan dengan penggunaan musik dalam lingkungan kelas, Bobbi deProter dkk., menyarankan penggunaan musik untuk: meningkatkan semangat, merangsang pengalaman, menumbuhkan relaksasi, meningkatkan fokus, membina hubungan, menentukan tema untuk hari itu, memberi inspirasi, bersenang-senang. ${ }^{31}$ Nyanyian-nyanyian yang digunakan dalam pembelajaran PAK selain untuk menyampaikan nilai-nilai edukatif kristiani, nyanyian-naynyian juga dapat meningkatkan semangat belajar naradidik, mengembangkan pengalaman naradidik terkait lirik yang ada di dalam nyanyian, menumbuhkan relaksasi yang bernilai edukatif kristiani karena ada pesan yang disampaikan di dalam nyanyian, menjadi fokus terkait dengan materi pembelajaran PAK, membina hubungan antarnaradidik yang menyanyikan bersama di dalam kelas, nyanyian yang dinyanyikan berkaitan dengan materi, nyanyian menjadi "jembatan" bagi materi yang hendak diajarkan, juga menjadi media rekreasi yang bernilai edukatif.

Rasul Paulus, dalam suratnya kepada Jemaat Efesus berkata, “...dan berkata-katalah seorang kepada yang lain dalam mazmur, kidung puji-pujian dan nyanyian rohani. Bernyanyi dan bersoraklah bagi Tuhan dengan segenap hati" (Ef 5:16). Sejalan dengan hal tersebut, Rasul Paulus menyarankan kepada jemaat di Kolose, "Hendaklah perkataan Kristus diam dengan segala kekayaannya di antara kamu, sehingga kamu dengan segala hikmat mengajar dan menegur seorang akan yang lain dan sambil menyanyikan mazmur, dan puji-pujian dan nynayian rohani, kamu mengucap syukur kepada Allah di dalam hatimu." Perkataan Paulus tersebut menjadai bagian yang sangat penting bagi para guru PAK dalam menggunakan nyanyian sebagai salah satu media pembelajaran yang efektif. Penggunaan nyanyian di dalam pembelajaran PAK dilakukan dengan segenap hati dan diekspresikan sesuai dengan makna dari nyanyian.

Penggunaan nyanyian di dalam kegiatan belajar-mengajar PAK di sekolah dapat terjadi di awal, di tengah, atau di akhir proses pembelajaran. Penggunaan nyanyian di awal pembelajaran PAK merupakan sebuah "jembatan" (bridge) kepada materi pembelajaran. Nyanyian yang dinyanyikan di bagian awal pembelajaran, sebelum atau setelah doa, sebaiknya berkaitan dengan materi pembelajaran sehingga naradidik sudah diajak dari awal pembelajaran untuk menghayati materi pembelajaran yang diajarkan.

Penggunaan nyanyian pada pertengahan pembelajaran merupakan cara guru PAK, bukan hanya sekadar sebuah rekreasi atau untuk mengisi waktu, melainkan lebih pada upaya untuk menjadikan musik (nyanyian) sebagai media penghantar pesan (materi) pembelajaran. Pada tahap ini nyanyian-nyanyian yang digunakan sebaiknya yang mengandung pesan terkait langsung dengan bagian materi yang sementara dibahas guru bersama naradidik. Bahkan, dapat juga guru PAK menggunakan nyanyian sebagai media pembelajaran secara langsung. Naradidik secara langsung belajar materi pembelajaran melalui nyanyian yang dinyanyian; di dalam nyanyian ada nilai-nilai edukatif kristiani, nilai-nilai edukatif dari materi pembelajaran PAK. Sementara penggunaan nyanyian di akhir pembelajaran PAK merupakan sebiah upaya sengaja dari guru PAK untuk memberikan penguatan kembali kepada naradidik tentang materi pembelajaran yang telah dilakukan bersama-sama.

Nyanyian-nyanyian yang akan dinyanyikan dalam pembelajaran PAK sebaiknya dilatih dengan sebaik-baiknya oleh guru agar dapat dinyanyikan sebagaimana tertulis di dalam penota-

${ }^{31}$ Bobbi dePorter, Mark Reardon, dan Sarah Singer-Nourie, Quantum Teaching, terjemahan Femmy wyarani (Boston: Allyn dan Bacon, 2000), 73-78. 
siannya (ada lirik dan lagu/melodinya). ${ }^{32}$ Penting untuk diketahui, bahwa nyanyian yang dinyanyikan dapat bertahan lama dalam ingatan setiap orang dan dapat dinyanyikan kembali pada waktu atau situasi-situasi tertentu, membangkitkan ingatan terhadap sesuatu, termasuk di dalamnya hal yang telah dipelajari. Jika nyanyian yang dinyanyikan oleh guru bersama dengan naradidik keliru, maka kekeliruan yang terjadi akan turut tersimpan di dalam memori setiap naradidik. Sebaliknya, jika yang dinyanyikan benar, maka hal tersebut akan tersimpan lama juga di dalam memori naradidik.

Sebaiknya guru PAK berusaha untuk mendapatkan nyanyian yang tidak hanya tertulis liriknya saja, tetapi juga lirik dan lagu (melodi), sehingga dapat mempelajari nyanyian yang hendak dinyanyikan dengan baik. Setelah mendapatkan nyanyian dengan penotasian yang lengkap. Tahap pertama yang dilakukan oleh guru adalah mempelajari lirik atau syair dari nyanyian tersebut untuk mengetahui makna dari nyanyian tersebut dan dapat mengekspresikan dengan baik. Kedua, guru mendeteksi kata atau frase yang mungkin sulit dimengerti oleh naradidik sehingga guru dapat memberikan penjelasan terkait dengan makna dari nyanyian yang dinyanyikan. Ketiga, guru PAK mempelajari melodi dari nyanyian yang akan dinyanyikan di dalam pembelajaran. Bagi para guru yang mengalami kesulitan untuk mempelejari melodi yang tertulis, guru dapat mencari orang yang dapat menolongnya untuk menyanyikan melodi dan nyanyian tersebut dengan benar dan merekamnya untuk selanjutnya dipelajari oleh guru. Nyanyikanlah melodi tersebut sampai guru mengingatnya. Hal lain yang dapat dilakukan adalah berusaha mendapatkan file midi atau video atau MP3 dari nyanyian tersebut dan berlatih secara mandiri untuk menguasai naynyain tersebut. Keempat, nyanyikanlah lirik atau syair dari nyanyian sesuai dengan melodi yang dibuat oleh penggubah nyanyian. Sedapat mungkin, nyanyikanlah sesuai dengan nada dasar yang ditetapkan oleh penggubah nyanyian. Jika nada dasar dari nyanyian $\mathrm{D}=1(\mathrm{do})$, latihlah nyanyian tersebut pada nada dasarnya dengan menggunakan alat penentu nada dasar, misalnya garputala atau penala, pianika, keyboard, piano, dan rekorder. Pada tahap ini, guru akan mengetahui apakah dengan nada dasar tersebut, nyanyian dapat juga dinyanyikan dengan baik oleh naradidik. Jika ternyata kurang sesuai, maka nada dasar dapat disesuaikan sehingga naradidik dapat bernyanyi dengan baik, tidak ketinggian atau kerendahan. Kelima, berlatih untuk menyanyikan nyanyian dengan menjiwai lirik/syair nyanyian sehiggga dapat mengekspresikan nyanyian dengan baik dalam pembelajaran PAK.

Jika nyanyian yang hendak dinyanyikan dalam pembelajaran belum diketahui oleh naradidik atau belum tetap dinyanyikan oleh naradidik, beberapa tahap berikut ini dapat dilakukan oleh guru PAK untuk membelajarkan nyanyian. Berikut ini salah satu contoh membelajarkan nyanyian (KJ. 36) yang dapat diterapkan dalam pembelajaran PAK di sekolah.

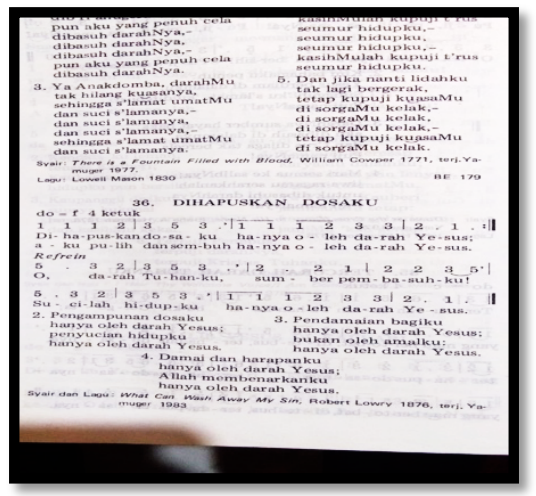

Gambar 1: Contoh Lagu dalam Kidung Jemaat 36

\footnotetext{
32 Sayangnya, tidak semua Sayangnya, banyak juga nyanyian yang ada di dalam buku teks pembelajaran PAK yang tidak disertai dengan notasi, hanya lirik atau syairnya saja, akibatnya para guru ada yang menyanyikan tidak sesuai dengan yang dibuat oleh penggubah nyanyian. Akibatnya sering terjadi sebuah nyanyian dinyanyikan berbeda di sekolah-sekolah. Untuk meminimalisir hal ini, sebaiknya guru PAK berupaya untuk mendapatkan nyanyian tersebut yang lengkap dengan notasinya. Jika hal ini tidak ditemukan, hal yang lain adalah berupaya untuk menemukan file midi atau video atau MP3 dari nyanyian tersebut kemudian belajar untuk menyanyikan nyanyian tersebut sehingga dapat digunakan secara baik dalam pembelajaran.
} 
Pertama, pastikan bahwa guru telah mengetahui nyanyian yang akan dinyanyikan. Pada tahap ini guru juga perlu membagi nyanyian ke dalam beberapa bagian sehingga dapat diajarkan secara bertahap kepada naradidik.

Dihapuskan dosaku hanya oleh darah Yesus

aku pulih dan sembuh hanya oleh darah Yesus

$\mathrm{O}$, darah Tuhanku, sumber pembasuhku!

Sucilah diriku hanya oleh darah Yesus

Kedua, saat pelaksanaan, pertama-tama, nyanyikanlah nyanyian tersebut secara keseluruhan kepada naradidik. Berikanlah kesempatan kepada anak-anak untuk mendengar guru menyanyikan nyanyian tersebut dengan benar. Ketiga, nyanyikanlah bagian pertama dari nyanyian dan diulangi oleh naradidik. Jika bagian yang pertama - Dihapuskan dosaku hanya oleh darah Yesus - belum dinyanyikan dengan benar oleh naradidik, guru kembali menyanyikan bagian pertama dan diulangi oleh naradidi. Jika bagian pertama telah dinyanyikan dengan benar, lanjutkan dengan bagian kedua - aku pulih dan sembuh hanya oleh darah Yesus. Jika bagian kedua belum dinyanyikan dengan benar, guru mengulangi menyanyikan bagian kedua dan diulang ulang naradidik. Jika bagian kedua telah dinyanyikan dengan benar, guru menyanyikan bagian pertama dan kedua - Dihapuskan dosaku hanya oleh darah Yesus aku pulih dan sembuh hanya oleh darah Yesus - dan diulangi oleh naradidik. Jika bagian ini belum benar, guru kembali menyanyikan dan dulangi oleh naradidik. Jika bagian pertama dan kedua telah dinyanyikan dengan benar dilanjutkan dengan bagian ketiga. Selanjutnya, dilakukan sampai semua bagian dinyanyikan atau keseluruhan nyanyian dinyanyikan. Berikut ini, urutan secara garis besar.

Guru menyanyikan bagian 1 diulangi oleh naradidik

Guru menyanyikan bagian 2 diulangi oleh naradidik

Guru menyanyikan bagian 1 dan 2 diulangi oleh naradidik

Guru menyanyikan bagian 3 diulangi oleh naradidik

Guru menyanyikann bagian 1, 2, dan 3 diulangi oleh naradidik

Guru menyanyikan bagian 1, 2, 3, dan 4 diulangi oleh naradidik

Guru dan naradidik kembali menyanyikan nyanyian tersebut

Bernyanyi merupakan salah satu kegiatan yang sering dilakukan oleh orang-orang Kristen. Sebagai bagian yang menyatu dengan kegiatan bernyanyi, nyanyian merupakan media yang perlu dikelola dengan baik. Penggunaan nyanyian secara bertanggung jawab dalam pembelajaran PAK akan memberikan pengaruh yang positif kepada naradidik. Bagi Vic Delamont, "Music could be used to teach in every class. People sometimes understand scriptural truths better when they are presented in song than when they are taught in lectures. ${ }^{\prime \prime 3}$ Musik dapat digunakan untuk mengajar di setiap kelas atau jenjang usia. Orang-orang akan lebih memahami Kitab Suci atau pengajaran Kristen secara lebih baik ketika hal tersebut disajikan di dalam nyanyian daripada melalui suatu pemikiran yang disampaikan dalam bentuk kuiah atau berceramah. Dengan demikian, penggunaan nyanyian sebagai salah satu media pembelajaran perlu dilakukan secara bertanggung jawab sehingga nilai-nilai edukatif kristiani yang terdapat di dalam materi-materi pembelajaran PAK di sekolah dapat dibelajarkan dengan baik.

\section{KESIMPULAN}

Musik merupakan salah satu karunia dari Allah yang dapat digunakan oleh guru PAK sebagai media pembelajaran yang efektif untuk membelajarkan iman Kristen kepada naradidik. Penggunaan musik, dalam hal ini nyanyian, secara bertanggung jawab dalam pembelajaran PAK akan berdampak pada pencapaian tujuan yang telah ditetapkan. Lebih daripada itu, musik (nyanyian) dapat menjadi salah satu media yang penting bagi guru PAK untuk membelajarkan naradidiknya

${ }^{33}$ Vic Delamont, The Ministry of Music in the Church (Chichago: Moody Press, 1980), 131,135,136; Bnd. Kemp. Helen, Music in Church Education With Children (Dallas: Chorister Guild Publishers, Second edition, 1975). 
menjadi orang-orang yang bijak di dalam iman Kristen. Pengunaan nyanyian di dalam pembelajaran PAK di sekolah dapat terjadi di awal atau di tengah atau di akhir pembelajaran. Penggunaan nyanyian sebagai media pembelajaran yang efektif dan penting dalam pembelajaran PAK di sekolah merupakan usaha yang perlu dilakukan oleh guru untuk menjembatani naradidik dengan materi pembelajaran, menjadi sumber belajar, dan penguatan kepada naradidik tentang materi yang dipelajari. Lebih daripadai itu, nyanyian dapat menjadi media pembelajaran yang efektif untuk mendidik orang-orang menjadi bijak di dalam iman Kristen.

Agar penggunaan nyanyian dalam pembelajaran PAK di sekolah dapat berdampak positif, maka guru PAK sebaiknya ingat bahwa nyanyian yang dinyanyikan akan tersimpan lama di dalam memori atau ingatan naradidik. Oleh karena ini penting bagi para guru PAK untuk menggunakan nyanyian dengan sebaik-baiknya, belajar untuk menyanyikannya dengan benar, baik dari segi melodinya tetapi juga menjiwai isi atau lirik yang ddinyanyikan sehingga dapat mengekspresikan nyanyian dengan baik. Guru PAK juga dapat membelajarkan nyanyian kepada naradidik dengan baik sehingga penggunaan nyanyian di dalam pembelajaran menjadi kegiatan yang berdampak positif bagi sikap, pengetahuan, dan keterampilan naradidik Kristen sehingga mereka menjadi anak-anak yang bijak dalam mengetahui, memahami, dan menyatakan iman Kristen.

\section{REFERENSI}

Borong Roberth P., dkk., penyunting, Berakar di dalam Dia dan Dibangun di atas Dia: 80 Tahun Prof Dr. P.D. Latuihamallo, Jakarta: BPK Gunung Mulia, 1998

Delamont Vic, The Ministry of Music in the Church, Chichago: Moody Press, 1980 dePorter Bobbi, Mark Reardon, dan Sarah Singer-Nourie, Quantum Teaching, terjemahan Femmy wyarani, Boston: Allyn dan Bacon, 2000

Gangel, Kenneth O., Building Leadership for Chruch Education, Chicago:Moody Publhiers, 1970

Groome, Thomas H., Sharing Faith: A Comprehensive Approach to Religious Education \& Pastoral Ministry: The Way of Shared Praxis, New York: HarperCollins Publishers, 1991

Haron, A. Rahman., Jamaludi Badusah, dan Zamri Mahamod, "Kemahiran Berfikir Aras Tinggi (KBAT) dalam Salak Didik dengan Elemen Nyanyian dan Elemen Pantun", Jurnal Pendidikan Bahasa Melayu -JPBM (Malay Language Education Journal -MyLEJ.

Hadi, Mohamad Sofyan, "The Use of Song In Teaching English for Junior High School Student", https://jurnal.umj.ac.id/index.php/ELIF, diakses 25 Oktober 2021.

Homrighausen. E.G., I.H. Enklaar, Pendidikan Agama Kristen, Jakarta: BPK Gunung Mulia, Cetakan XIX, 2005

Ismail Andar, penyunting, Ajarlah Mereka Melakukan: Kumpulan Karangan Seputar Pendidikan Agama Kristen, Jakarta: BPK Gunung Mulia, Cetakan I, 1998.

Jones, L. Gregory., Stephanie Paulsell, editors, The Scope of Our Art: The Vocation of the Theological Teacher, Grand Rapids: William B. Eerdmans Publishing Company, 2002), 100.

Kemp. Helen, Music in Church Education With Children, Dallas: Chorister Guild Publishers, Second edition, 1975.

Leigh Ronald W., terjemahan Stephen Suleeman, Melayani dengan Efektif (Jakarta: BPK Gunung Mulia, cetakan III, 1996).

Mawene. Gereja yang Bernyanyi: Menghidupkan Ibadah dengan Lagu, Yogyakarta, ANDI Offset, Cetakan IV, 2007

Melchert, Charless F. Wise Teaching: Biblical Wisdom and Educational Ministry, Pennsylvania: Trinity Press International, 1998.

Miller, Randolph Crump. Education for Christian Living. second edition, Englewood Cliffs: Prentice-Hall, Inc., 1963.

Pantun, Reney. "Penggunaan Teknik Nyanyian dalam Meningkatkan Kefahaman Murid Tahun Dua dalam Topik Pembundaran", http://ojs.umsida.ac.id/index.php/icecrs 
Sanjaya, Wina. Strategi Pembelajaran Berorientasi Standar Proses Pendidikan, Jakarta: Kencana Prenada Media Group, Cetakan V, 2008.

Seymour, Jack L., Donald E. Miller,. Theological Approaches to Christian Education, Nashville: Abingdon Press, 1990.

Seymour, Jack L., Margaret Ann Crain, Joseph V. Cockett, Educating Christians: The Intersection of Meaning, Learning, and Vocation, Nashville: Abingdon Press, 1993.

Smith, David I., James K. A. Smith. "Introduction: Practices, Faith," and Pedagogy dalam David I. Smith, James K. A. Smith, editors, Teaching and Christian Practices: Reshaping Faith \& Learning, Grand Rapids: William B. Eerdmans Publishing Company, 2011.

Taylor. J., edited, An Introduction to Christian Education, Nashville: Abingdon Press, 1966.

Usman Moch Uzer. Menjadi Guru Profesional, Bandung: Rosda Karya, 1990.

Tim Redaksi PAK-PGI, Buku Siswa Pendidikan Agama Kristen (KTSP), Jakarta: BPK Gunung Mulia, I-VI, 2008.

Woods, Robert., Bran Walrath. The Message in the Music: Studying Contemporary Praise \& Worship, Nashville: Abingdon Press, 2007.

Wyckoff, D. Campbell. The Task of Christian Education, Philadelphia: The Westminster Press, 1955.

Yamuger, Pelengkap Kidung Jemaat, Jakarta: Yamuger, cetakan IV, 2007.

-------, Kidung Ceria, Jakarta: Yamuger, Cetakan XI, 1985

, Buku Nyanyian Kidung Sekolah Minggu, Jakarta: Yamuger, Cetakan I, 2008. 